\title{
African Swine Fever in the Russian Far East (2019-2020): Spatio-Temporal Analysis and Implications for Wild Ungulates
}

\author{
Olga I. Zakharova ${ }^{1 *}$, llya A. Titov², Andrey E. Gogin ${ }^{2}$, Timofey A. Sevskikh², \\ Fedor I. Korennoy ${ }^{1,3}$, Denis V. Kolbasov ${ }^{2}$, Levon Abrahamyan ${ }^{4 *}$ and Andrey A. Blokhin ${ }^{1}$ \\ ${ }^{1}$ Federal Research Center for Virology and Microbiology, Branch in Nizhny Novgorod, Nizhny Novgorod, Russia, ${ }^{2}$ Federal \\ Research Center for Virology and Microbiology, Pokrov, Russia, ${ }^{3}$ Federal Center for Animal Health (FGBI ARRIAH), Vladimir, \\ Russia, ${ }^{4}$ Swine and Poultry Infectious Diseases Research Center (CRIPA) and Groupe de Recherche sur les Maladies \\ Infectieuses en Production Animale (GREMIP), Faculty of Veterinary Medicine, University of Montreal, Saint-Hyacinthe, QC, \\ Canada
}

\section{OPEN ACCESS}

Edited by:

Shao-Lun Zhai,

Guangdong Academy of Agricultural

Sciences, China

Reviewed by:

Chang Cai,

Zhejiang Agriculture and Forestry

University, China

Marie Rene Culhane,

University of Minnesota, United States

*Correspondence:

Olga I. Zakharova

olenka.zakharova.1976@list.ru

Levon Abrahamyan

levon.abrahamyan@umontreal.ca

Specialty section:

This article was submitted to

Veterinary Infectious Diseases,

a section of the journal

Frontiers in Veterinary Science

Received: 11 June 2021

Accepted: 12 July 2021

Published: 05 August 2021

Citation:

Zakharova OI, Titov IA, Gogin AE,

Sevskikh TA, Korennoy FI,

Kolbasov DV, Abrahamyan $L$ and

Blokhin AA (2021) African Swine Fever in the Russian Far East (2019-2020):

Spatio-Temporal Analysis and Implications for Wild Ungulates.

Front. Vet. Sci. 8:723081.

doi: 10.3389/fvets.2021.723081
African swine fever (ASF) is an emerging viral contagious disease affecting domestic pigs (DP) and wild boar (WB). ASF causes significant economic damage to the pig industry worldwide due to nearly $100 \%$ mortality and the absence of medical treatments. Since 2019, an intensive spread of ASF has been observed in the Russian Far East region. This spread raises concerns for epidemiologists and ecologists given the potential threat to the WB population, which is an essential member of the region's wild ungulates and provides a notable share of food resources for predatory species. This study aims to determine the genotype of ASF virus circulating in the region, reveal the spatio-temporal patterns of the ASF outbreaks' emergence, and assess the potential reduction of the regional fauna because of expected depopulation of WB. The first historical case of ASF in the study region was caused by an African swine fever virus (ASFV) isolated from DPs and belonging to Genotype 2, CVR1; IGR-2 (TRS +). Sequencing results showed no significant differences among ASFV strains currently circulating in the Russian Federation, Europe, and China. The spatiotemporal analysis with the space-time permutations model demonstrated the presence of six statistically significant clusters of ASF outbreaks with three clusters in DPs and one cluster in WBs. DP outbreaks prevail in the north-west regions of the study area, while northern regions demonstrate a mixture of DP and WB outbreaks. Colocation analysis did not reveal a statistically significant pattern of grouping of one category of outbreaks around the others. The possible damage to the region's fauna was assessed by modeling the total body mass of wild ungulates before and after the wild boars' depopulation, considering a threshold density of WB population of 0.025 head $/ \mathrm{km}^{2}$, according to the currently in force National Plan on the ASF Eradication in Russia. The results suggest the total mass of ungulates of the entire study region will likely decrease by $8.4 \%$ (95\% Cl: 4.1-13.0\%), while it may decrease by 33.6\% (19.3-46.1\%) in the Primorsky Krai, thereby posing an undeniable threat to the predatory species of the region.

Keywords: African swine fever virus, cluster analysis, depopulation, Far East of Russia, genotyping, ungulates, wild boar 


\section{INTRODUCTION}

African swine fever (ASF) is among the most dangerous diseases of swine and is known to cause considerable damage to pig production in many countries worldwide (1-5).

The ASF virus (ASFV) belongs to the Asfarviridae family and affects both domestic pigs (DP) and wild boars (WB). At present, the genetic characteristics of the ASFV are represented by 23 genotypes associated with geographical locations, characterizing the complexity of the virus epidemiology (3, 6-9). ASF epidemics currently occurring in Europe can be treated as two clusters of outbreaks. One of the clusters is located in Sardinia (Italy), where the disease was registered in 1978 and is represented by ASFV strains belonging to genotype 1 (10). The second cluster is widespread in North-Eastern Europe and the Russian Federation caused by strains of the ASFV belonging to genotype 2 (4). The latter is highly virulent, causing acute disease and resulting in mortality rates of $94.5-100.0 \%$ in both WB and DP (11-15).

The transcontinental transmission of the ASFV in Georgia in 2007, has resulted in the introduction of the disease into the Russian Federation. The first outbreak of the region was registered in WB in the Chechen Republic (November 2007), with subsequent spread of the virus in the Russian Federation and neighboring European countries (16). The nosoareal of the ASF has recently expanded, reaching the Russian Far East (Figure 1) and affecting many countries in South-East Asia (11, 17-21). While insufficient biosecurity on pig farms is considered the main factor in disease spread (22-26), the presence of WB in an ecosystem plays an important role in virus transmission, which is acknowledged by many countries $(22,27,28)$.

In some countries with recorded ASF infections, WB populations play the role of an epidemiological reservoir and maintain the virus in the environment. The virus enters $\mathrm{WB}$ populations mainly through the animals coming into contact with DP and eating contaminated feed and swill $(29,30)$.

Wild boars and DP belong to the same species (Sus scrofa), as WB are the ancestors of DP. Therefore, the transmission of pathogens is likely bidirectional (31). Wild boars are susceptible to many infections. Although ASF is associated with high mortality, its prevalence in the population does not exceed 3\% (32). Nevertheless, every year in the Russian Federation, as in many countries in Europe and Asia, new cases of ASF occur in WB. Proper disposal of infected carcasses (corpses) in compliance with biosafety measures and proper diagnostics for every infected animal are among the essential measures needed to break the ASF transmission cycle $(24,33)$.

Humans can affect the fluctuations in the numbers of WB, ranging from the maximum possible protection of these animals to their complete eradication. Hunting is the most important risk factor for decline in the $\mathrm{WB}$ population, which not only determines their population dynamics, but also has a significant impact on the sex, age, and spatial structure of their populations. Furthermore, WB are the most important hunting trophies and the main prey of large predators (34-37).

One of the measures that has been proposed to control ASF spread is the depopulation of WB, i.e., reducing their numbers to a certain threshold at which the virus' intra-population transmission will stop or significantly slow down owing to the decrease of contact ratio $(4,27,38)$. As WB present a significant share of the food resource for many wild predatory species, a decrease in their numbers could disturb the equilibrium of the entire ecosystem and lead to a corresponding decrease in the predator population (39-41). Among the predators of the Russian Far East, the Siberian tiger (Panthera tigris altaica) merits mention as a rare protected species, whose population in the region is currently estimated at around 500 individuals (https:// wwf.ru/en/regions/amur/amurskiy-tigr/).

Thus, the aims of this study were (1) to conduct an epidemiological and genetic analysis of the ASF situation in the Far Eastern region of Russia, from 2019-2020, and (2) to assess a possible size of WB depopulation and its impact on the whole wild ungulate population of the study region.

\section{MATERIALS AND METHODS}

\section{Study Area}

In this study, we considered the ASF epidemic situation in the following four administrative divisions located in the Far Eastern Russian Federation: Primorsky Krai, Khabarovsk Krai, the Jewish Autonomous Oblast, and Amur Oblast (Figure 2). These regions are part of the Far Eastern Federal District of the Russian Federation and were selected because the ASF virus was first detected in this region in 2019. The total area of the study region exceeds $1,350,400 \mathrm{~km}^{2}$ with a mean population density of about three people $/ \mathrm{km}^{2}$. The natural conditions in these areas vary significantly due to the vast extent of the territory from North to South. The climate of the coastal strip in the Far East is relatively warm, humid, and monsoonal. The winters in the Far East are cold and dry, and the summers are hot in continental areas and cool in coastal areas. The climatic conditions in these regions have a huge influence on their economic development. The four aforementioned areas have a rich hydrographic network (http://assoc.khv.gov.ru/regions/ information/geography-climate). The leading economic sectors are fishing, forestry, and ore mining. This territory in the Far East contains the country's main ecological reservoir; there are 25 natural reserves and three national parks. A unique feature of this region is the population of Siberian tigers, which is an endangered species listed in the Red Book of the International Union for Conservation of Nature (http://www. nparks.ru/fareast_zapovednik.php).

\section{Data and Sources}

To analyze the epidemic situation, the data on ASF outbreaks notified by the Russian Federation to the OIE from 2019 to 2020 were retrieved from the FAO EMPRES-i database (http://empresi.fao.org/eipws3g/). The database contains information on 205 ASF outbreaks in the study region for the period from 30 Jul 2019 to 27 Dec 2020, of which $71(35 \%)$ were in WB and $134(65 \%)$ in DP (Figure 2).

Samples of biological material for the phylogenetic study of the ASF virus were obtained from domestic pigs as a result of monitoring studies in an individual private farm in the village of 


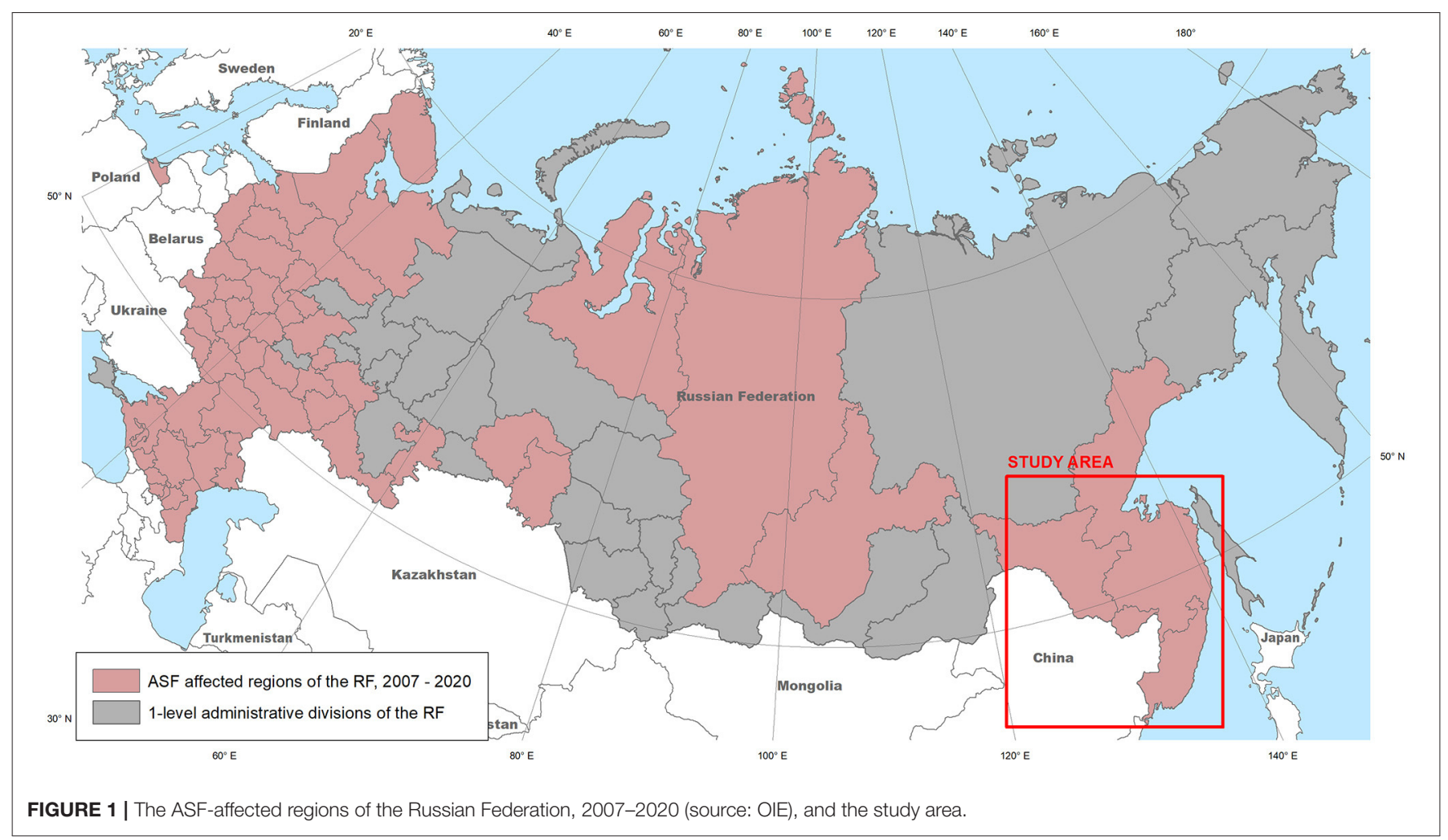

Ust-Ivanovka, Blagoveshchensk District, Amur Oblast and site of the third reported outbreak in the study area (Figure 2).

Data on the population size of WB and other ungulates in the study area were obtained from the Ministry of Natural Resources and Environment of the Russian Federation statistical reports for 2019 (https://www.mnr.gov.ru/en/). Data on wild ungulates' body mass were retrieved from Sokolov (42) and Danilkin (43). The current number of Siberian Tigers in the study area is estimated as $\sim 500$ heads, of which $90 \%$ live in Primorsky Krai (the World Wildlife Fund (WWF) reports https://wwf.ru/species/ amurskiy-tigr/vsye-ob-amurskom-tigre-khozyaine-taygi/). The population density of ungulates was calculated based on the forestry area of the region, which has been retrieved from the Unified Interdepartmental Information and Statistical System UIISS (https://www.fedstat.ru/indicator/38194).

\section{Sequencing and Phylogenetic Analysis of ASFV}

ASF virus “Amur Region/08/19/19," identified in 2019 during monitoring studies was used in this research. Phylogenetic studies were conducted by the Laboratory for Diagnostics and Monitoring of the Federal Research Center for Virology and Microbiology (https://ficvim.ru/en/). Confirmation of the presence of viral genome fragments in nucleic acid samples was carried out by real-time PCR (44). DNA was extracted using a commercial DNA sorb kit (Interlabservis, Russia) in accordance with the manufacturer's instructions. Then, the samples that were identified as positive by real-time PCR were subjected to sequencing of following fragments: B646L, E183L, I73R/I329L,
B602L, EP402R, and MGF 505-9R. Of these, the B646L and E183L fragments were chosen as genotype determining genes. The other gene fragments were recommended by the OIE ASF reference laboratory (Madrid, Spain) for molecular characterization of ASF virus strains and isolates $(8,45-49)$.

PCR was performed using specific primers and Quick-Load ${ }^{\circledR}$ Taq 2X Master Mix (NEB, USA). The PCR products were purified using a MinElute Gel Extraction Kit (Qiagen, Germany). DNA sequencing was performed using an ABI 3130 Genetic Analyzer (Applied Biosystems, USA). The samples were prepared using BigDye Terminator v.3.1 cycle sequencing kit followed by a purification step with BigDye XTerminator ${ }^{\mathrm{TM}}$ Purification Kit (both from Applied Biosystem, Foster City, CA, USA) according to the manufacturer's instructions.

BioEdit v7.0.4.1. was used to obtain a consensus sequence (50). The sequences were aligned using ClustalX (51). The sequence data of an ASF virus isolate were subjected to BLAST analysis using the NCBI BLAST tool (https://blast.ncbi.nlm.nih.gov/ Blast.cgi) and were compared with sequences of commonly used reference strains and other strains represented in the GenBank (https://www.ncbi.nlm.nih.gov/genbank). Phylogenetic trees were constructed using the maximum likelihood method in which phylogenetic distances were estimated using Kimura's two-parameter model (K2P) (52) in the MEGA 7 program (53).

\section{Space-Time Data Analysis}

A space-time cluster analysis using the space-time permutation model (54) was applied to detect a potential clustering of ASF outbreaks within the study area. This type of analysis allows 


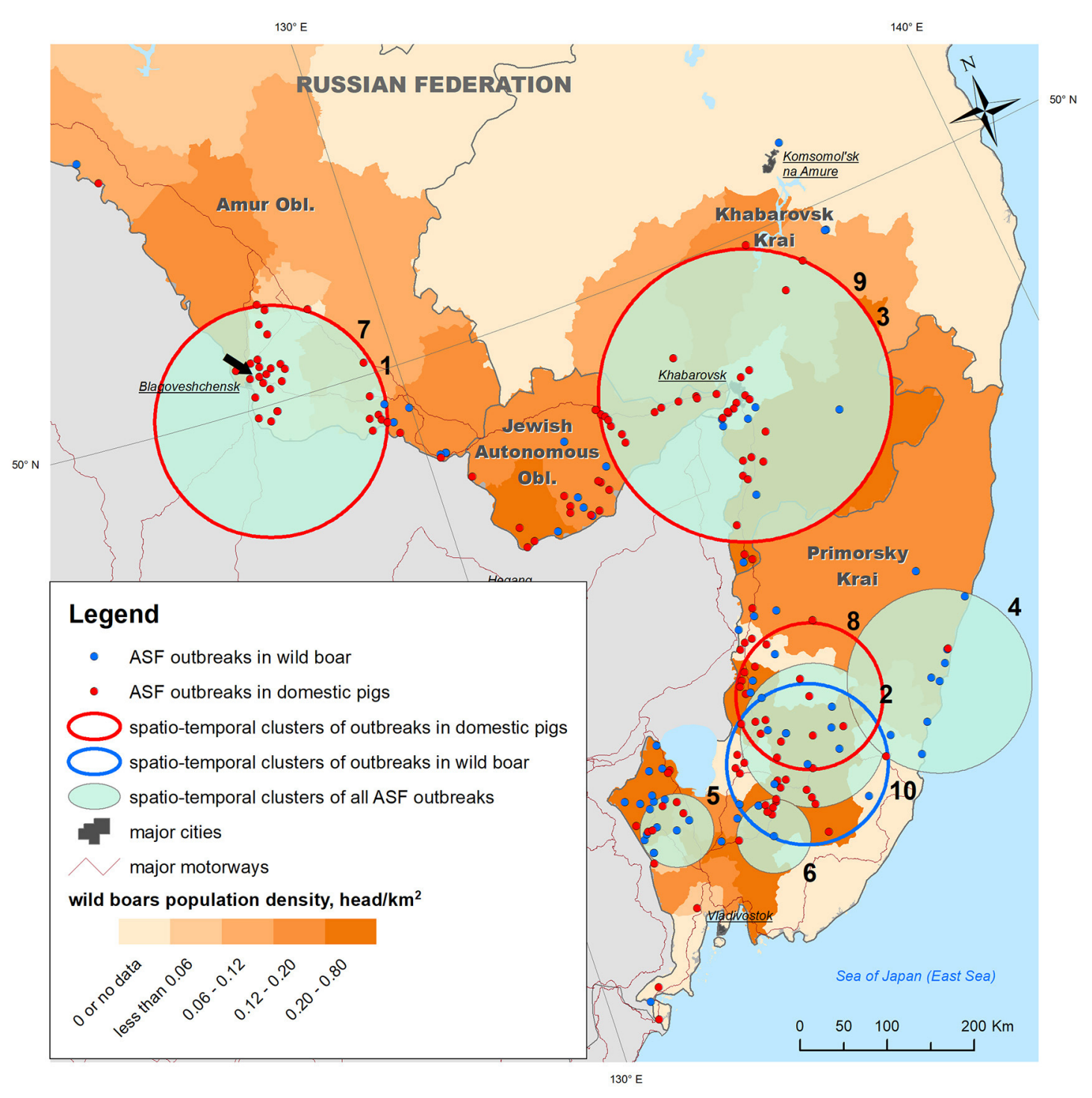

FIGURE 2 | ASF outbreaks (OIE, 2019-2020) and revealed spatio-temporal clusters of outbreaks plotted against wild boar density in the Far East regions of Russia. The black arrow points to the outbreak from which the biological material for ASFV phylogenetic analysis was sampled.

circular areas to be identified where the observed concentrations of outbreaks over a certain time period are significantly higher than would be expected based on the null hypothesis of the random distribution of outbreaks in space and time. The maximum radius and duration of the clusters were taken to be $50 \%$ of the whole study area and period, respectively. Clusters where the observed distribution of outbreaks differed from the hypothetical random distribution at levels of significance $>95 \%$ ( $p \leq 0.05)$ were considered statistically significant. The ODE value (observed/expected) expresses the ratio of the number of outbreaks observed in a cluster to the expected one. Clusters were detected for: (i) all outbreaks; (ii) DP outbreaks only, and (iii) WB outbreaks only.
To visualize the movement of the ASF epidemic since its first emergence within the study area, we applied mapping of the ASF outbreaks' median centers by month using the Median Center GIS (Geographic Information Systems) procedure (55). For each month of the analyzed period, this tool calculates a median point that provides a minimized overall Euclidean distance to all other ASF outbreaks' locations. This median center can be sought as a conventional measure of central tendency less sensitive to spatial outliers than a mean center.

To explore a potential relationship between the ASF outbreaks in DP and WB, we applied a GIS technique named Colocation Analysis. This technique measures local patterns of spatial association between two categories of point features using the 
colocation quotient statistics (56-58). Given two categories of interest in the study area, namely $\mathrm{A}$ and $\mathrm{B}$, the colocation quotient (CQ) expresses a local proportion of category B points within a defined neighborhood of category A points. Category B points are then randomly permuted within the whole study area to estimate whether their observed distribution differs from a random one and to obtain a $p$-value. If the above proportion is higher than a global proportion of category $\mathrm{B}$, the $\mathrm{CQ}$ will be $>1$. Otherwise, the CQ will be below 1 . The $p$-value obtained determines the statistical significance of the revealed pattern. Given that colocation analysis is not symmetric, we explored relationships between (i) DP and WB, and (ii) WB and DP outbreaks. To provide a neighborhood for the CQ calculation we tested circular bands of the radius equal to the mean neighboring distance for the whole set of ASF outbreaks (i), and of the radius equal to $150 \mathrm{~km}$ (ii) based on the previous studies on ASF outbreaks clustering $(59,60)$. To add an epidemiological meaning to the analysis of relationship between ASF outbreaks, we analyzed colocation using space-time window accounting for a time span of 2 weeks before and after the analyzed outbreaks that reflects our assumption on the average duration of infectious period in acute ASF course (https://www.oie.int/app/uploads/2021/03/ african-swine-fever.pdf). This method reflects an assumption that a certain ASF outbreak might be epidemiologically related to a previous outbreak of the other category within the allowed time period (i.e., an outbreak in DP might be resulted by bringing the virus by infected WB from close neighborhood; or WB outbreak might be caused by contaminated waste or improperly utilized pig carcasses from a preceding DP case).

\section{Estimation of the Size of the Expected WB Depopulation}

According to some studies, decreases in wild boar (WB) populations have been shown to be a requisite measure to prevent the transmission of ASFV in these populations $(3,6,24,37)$. In the currently in force national guidelines to prevent and eradicate ASF in the Russian Federation (61), a value of 0.25 boars/1,000 ha $\left(0.025\right.$ boars $\left./ \mathrm{km}^{2}\right)$ is recommended as a threshold host density that should be maintained in order to interrupt the circulation of the ASF virus in the WB population within an infected area. Assuming that such a measure may be undertaken in the study region, in this paper we used the above value to estimate the expected size of the WB depopulation.

\section{Estimation of the Possible Decrease in the Total Mass of the Wild Ungulates}

To estimate the possible reduction of the food resource for predatory species of the region, a total mass of ungulates living in the study area was assessed: (1) in 2019, before the ASF virus was introduced to this region; and (2) after the decrease of WB number due to expected WB depopulation, considering a threshold density of $0.025 \mathrm{head} / \mathrm{km}^{2}$. Wild boar, musk deer, roe deer, wild reindeer, moose, and red deer are typical ungulates of the region $(39,40,62)$. The body mass of each animal was modeled using a uniform distribution based on maximum and minimum estimates taken from the literature (42). Modeling was performed using a Monte Carlo simulation with 10,000 iterations, which allowed the mean and 95\% confidence interval of the ungulates' summary body mass to be estimated. The decrease in the total ungulate mass was assessed: (1) for the whole study area and (2) for only Primorsky Krai, which is home to $90 \%$ of the entire Siberian tiger population of the study area and has the highest number of WB.

\section{Software}

The cluster analysis was performed using SaTScan software (59). The statistical processing of the data was performed using MS Office Excel application package (Microsoft, Redmond, WA, USA) with @Risk simulation modeling add-on v.6.3 (Palisade Inc., Ithaca, NY, USA). The spatial analysis and results' visualization were carried out using ArcGIS Desktop 10.8.1 and ArcGIS Pro 2.6.3 (Esri, Redlands, CA, USA).

For phylogenetic analysis, BioEdit v7.0.4.1 software (50) was used to obtain a consensus sequence. Nucleotide sequences were aligned with ClustalX (51). To build a phylogenetic tree, the MEGA 7 package (53) was used. To perform a phylogenetic analysis, the analyzed sequences were compared with homological ASFV gene sequences from GenBank database with BLASTN (http://blast.ncbi.nlm.nih.gov/Blast.cgi).

\section{RESULTS}

\section{Spatio-Temporal Analysis of ASF in the Far East}

The analysis of the ASF spread within the study area from its introduction in July 2019 to December 2020, showed that the disease has become widespread over a large territory in Primorsky Krai, the Jewish Autonomous Oblast, Amur Oblast, and Khabarovsk Krai, and mainly concentrated along the Russian-Chinese border. Distribution of outbreaks shows certain spatial heterogeneity across the study area. Outbreaks in WB were mainly observed in Primorsky Krai and Jewish Autonomous Oblast, both of which have the highest density of WB population, while outbreaks in DP were more evenly distributed across the study region, demonstrating a high concentration in Amur Oblast with no WB outbreaks in the same area.

Space-time cluster analysis revealed six statistically significant clusters of ASF outbreaks; three statistically significant clusters of outbreaks in DP, and just one cluster of outbreaks in WB (Table 1 and Figure 2). Two of all ASF outbreaks' clusters demonstrate full spatio-temporal coincidence with clusters in DP (\#1 and 7 in Amur oblast, \#3 and 9 in Jewish Autonomous Oblast and Khabarovsk Krai) suggesting that those clusters are formed only by the outbreaks in DP. The clustering pattern is more heterogeneous in Primorsky Krai where four spatiotemporal cluster are formed by a mixture of DP and WB outbreaks, with just single clusters in DP and WB, respectively. The latter clusters do not coincide but demonstrate some spatial and temporal overlap. However, moving north-west along the Russian-Chinese border, DP, and WB outbreaks become more spatially separated with the dominance of DP cases.

Calculation of the outbreaks' median centers by month demonstrates that ASF almost simultaneously emerged in 
TABLE 1 | Characteristics of spatiotemporal clusters of ASF outbreaks in domestic pigs and wild boar in the Far East of Russia, $2019-2020$.

\begin{tabular}{|c|c|c|c|c|c|c|c|c|}
\hline Cluster \# & $\begin{array}{l}\text { Territorial } \\
\text { coverage }\end{array}$ & $\begin{array}{l}\text { Cluster radius, } \\
\text { km }\end{array}$ & $\begin{array}{c}\text { Observed } \\
\text { number of } \\
\text { outbreaks (in } \\
\text { population) }\end{array}$ & $\begin{array}{l}\text { Observed to } \\
\text { expected rate } \\
\text { ODE }\end{array}$ & $\begin{array}{l}\text { Start } \\
\text { date }\end{array}$ & $\begin{array}{l}\text { End } \\
\text { date }\end{array}$ & $\begin{array}{c}\text { Cluster duration, } \\
\text { days }\end{array}$ & $P$-value \\
\hline 1 and 7 & Amur oblast & 138 & $26^{\star}(\mathrm{DP})$ & $\begin{array}{l}4.1 \text { for all } \\
\text { outbreaks, } 2.8 \text { for } \\
\text { DP cluster }\end{array}$ & 16.08.2019 & 26.09 .2019 & 41 & $<0.001$ \\
\hline 2 & Primorsky Krai & 86 & 17 (DP+WB) & 5.8 & 28.02.2020 & 30.07 .2020 & 153 & $<0.001$ \\
\hline 3 and 9 & $\begin{array}{l}\text { Jewish } \\
\text { Autonomous } \\
\text { Oblast and } \\
\text { Khabarovsk Krai }\end{array}$ & 175 & $29^{*}(\mathrm{DP})$ & $\begin{array}{l}3.0 \text { for all } \\
\text { outbreaks, } 2.5 \text { for } \\
\text { DP cluster }\end{array}$ & 31.07 .2020 & 17.09.2020 & 48 & $<0.001$ \\
\hline 4 & Primorsky Krai & 110 & 10 (DP+WB) & 8.5 & 16.10.2020 & 10.12 .2020 & 55 & $<0.001$ \\
\hline 5 & Primorsky Krai & 44 & 10 (DP+WB) & 6.8 & 06.12 .2019 & 20.02.2020 & 76 & 0.002 \\
\hline 6 & Primorsky Krai & 44 & 10 (DP+WB) & 6.2 & 21.08.2020 & 15.10 .2020 & 55 & 0.007 \\
\hline 8 & Primorsky Krai & 88 & $12^{\star}(\mathrm{DP})$ & 5.9 & 29.05.2020 & 30.07 .2020 & 62 & $<0.001$ \\
\hline 10 & Primorsky Krai & 96 & 10 (WB) & 5.0 & 28.02.2020 & 15.10 .2020 & 230 & $<0.001$ \\
\hline
\end{tabular}

DP, domestic pigs; WB, wild boars. Cluster numbers correspond to Figure 2.

*Several WB outbreaks within the cluster do not belong to the cluster time period.

different regions of the study area adjoining the People's Republic of China: in WB of Primorsky Krai (July 2019) and in DP of Amur Oblast (August 2019). The former region presents a forestry area with the highest density of WB in the region, while the latter is a suburb of Blagoveschensk city that features a direct transport connection with China by a bridge across the Amur River. The direction of median centres' spread suggests consequent epidemic movement from both initial areas north and east with the concentration of most recent outbreaks in Khabarovsk Krai. The direction coincides with the main transportation routes in the region (Figure 3).

The mean neighboring distance between all ASF outbreaks within the study area calculated with The Mean Nearest Neighbor GIS tool was found to be $15 \mathrm{~km}$. The colocation analysis of the ASF outbreaks in DP with outbreaks in WB (i.e., testing for an elevated concentration of WB outbreaks in close vicinity to DP outbreaks within 2-weeks time period) showed that:

- Within a neighborhood of $15 \mathrm{~km}$ radius, no DP outbreaks were statistically significant collocated with WB outbreaks; only 3 out of 134 (2.2\%) DP outbreaks demonstrated statistically non-significant $(p>0.05)$ colocation with WB outbreaks, while $70(52.2 \%)$ DP outbreaks were found to be statistically non-significant isolated;

- Within a neighborhood of $150 \mathrm{~km}$ radius, three (2.2\%) DP outbreaks were statistically significant $(p<0.05)$ collocated with WB outbreaks (in Primorsky Krai), while 53 DP outbreaks were found to be statistically significant isolated throughout the study area (Figure 4).

The colocation analysis of WB outbreaks with DP outbreaks (i.e., testing for an elevated concentration of DP outbreaks in close vicinity to WB outbreaks within 2-weeks time period) demonstrated that:
- Within a neighborhood of $15 \mathrm{~km}$ radius, no WB outbreaks were found to be statistically significant collocated with DP outbreaks, while three (4.2\%) and 17 (23.9\%) of WB outbreaks were statistically non-significant collocated and isolated with DP outbreaks, respectively;

- Within a neighborhood of $150 \mathrm{~km}$ radius only one (1.4\%) WB outbreak was statistically significant collocated with DP outbreaks (in Jewish Autonomous Oblast), and six (8.5\%) WB outbreaks were statistically significant isolated (in Primorsky Krai), while $10(14.0 \%)$ and 43 (60.6\%) WB outbreaks were statistically non-significant collocated and isolated, respectively (Figure 5).

\section{Sequencing and Phylogenetic Analysis for ASFV}

TheB646L, E183L, I73R/I329L, B602L, EP402R, and MGF 505-9R gene sequences of the Amur/19.08.19 strain were deposited in GenBank under the accession numbers MT840357, MT840356, MT840354, MT840352, MT840355, and MT840353, respectively.

The phylogenetic analysis of ASFV isolates of the Amur/19.08.19 strain was based on a fragment of the B646L gene sequence, which encodes the P72 protein. The analysis revealed that this strain belongs to the second genotype. This genotype was initially widely spread in Eastern Europe, when it was first reported in Georgia, in 2007. Genotypic affiliation of the Amur/19.08.19 strain was also confirmed by calculating the phylogenetic tree using the nucleotide sequencing of the E183L gene, encoding the P54 protein (Figure 6).

No changes were detected in the central variable region (CVR) of the genome, which includes the B602L gene. Thus, studied ASFV isolates belong to the CVR1 variant (according to OIE ASF reference laboratory classification [Madrid, Spain]). Moreover, these isolates belonged to the TRS+ (IGR2) variant by classification, based on I73R/I329L sequence (Figure 7). 


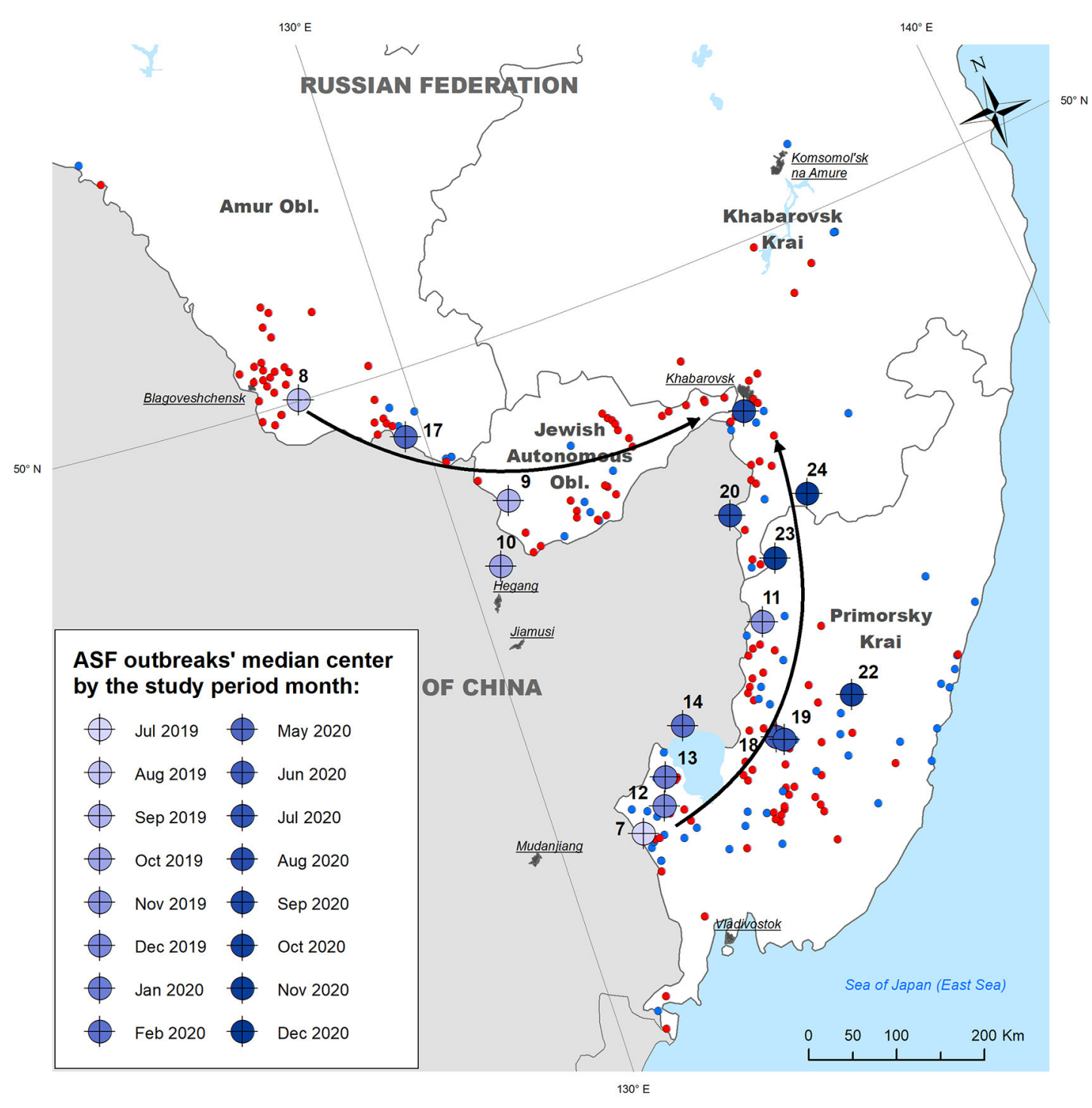

FIGURE 3 | Median centers of ASF outbreaks in the Far East region of Russia by month from July 2019 to December 2020. Arrows indicate the apparent direction of the epidemic movement.

Nucleotide substitutions in the sequences of the EP402R and $M G F$ 505-9R genes were also not detected.

\section{Assessment of the Decrease in Wild Ungulates' Mass After WB Depopulation}

The number of wild ungulates, including the WB, based on the administrative divisions of the study area is shown in Table 2 (as of 2019). The table also presents the estimates of total mass of all ungulates for 2019 as well as after the expected depopulation of WB until a threshold density of 0.025 head $/ \mathrm{km}^{2}$. The results suggest that the WB population may potentially be reduced by $93 \%$ in Primorsky Krai, by $91 \%$ in the Jewish Autonomous Oblast, by $46 \%$ in Amur Oblast, and by $8 \%$ in Khabarovsk Krai.
As a result of $\mathrm{WB}$ number decline, the total mass of all wild ungulates may decrease by $8.4 \%$ (95\% CI: $4.1-13.0 \%$ ) in the whole study area, while the reduction may be as high as $33.6 \%$ (19.3-46.1\%) in Primorsky Krai, which is home to the majority of the Siberian tiger population.

\section{DISCUSSION}

The observed pattern of the ASF outbreaks' clustering within the study area likely reflects the multiple ways through which the virus may have entered this region. The initial spread started simultaneously in two distant parts of the study region (Primorsky Krai and Amur Oblast) and resulted 


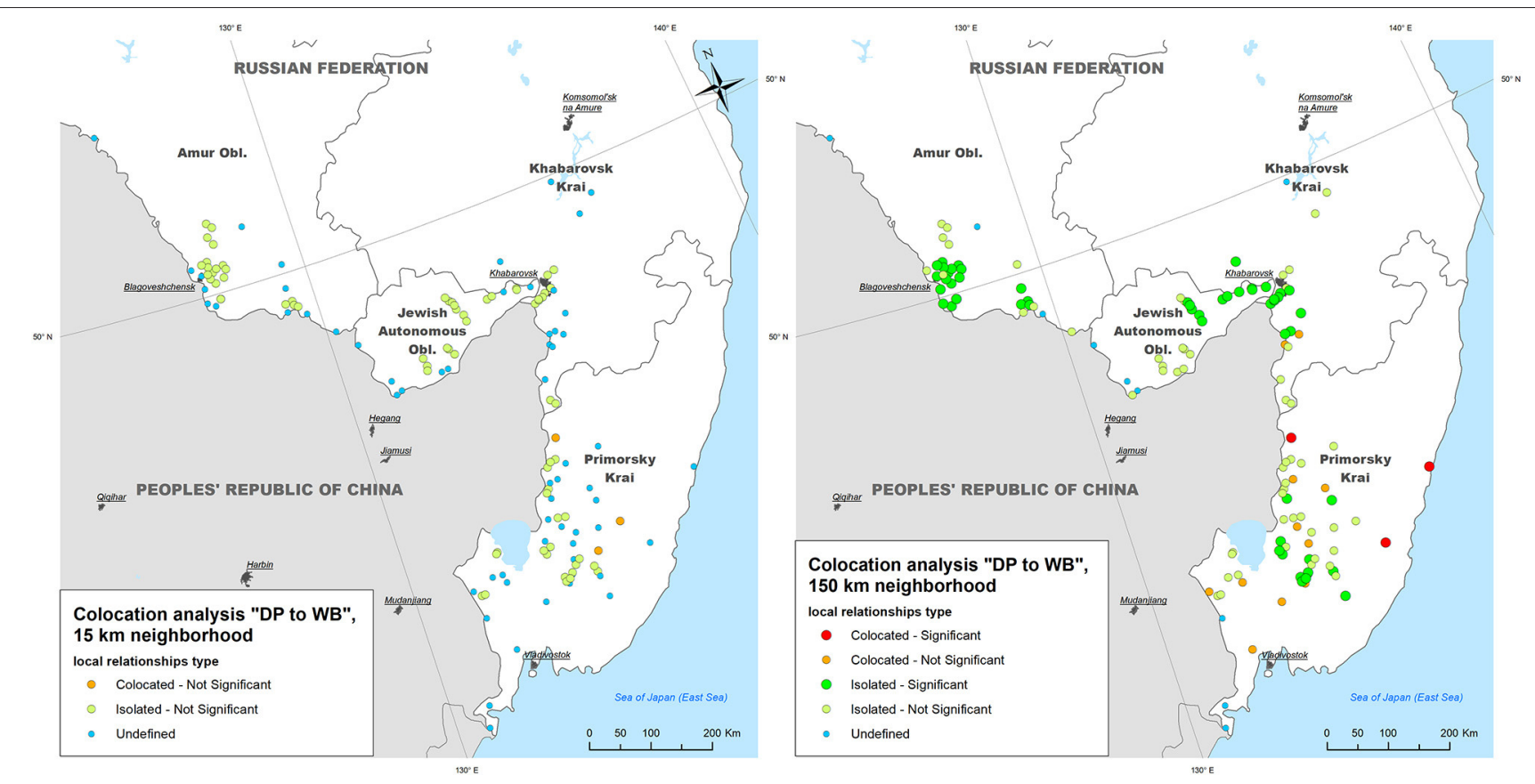

FIGURE 4 | The results of local colocation analysis of ASF outbreaks in domestic pigs (DP) and wild boar (WB). (Left) With $15 \mathrm{~km}$ as a neighboring distance; (Right) with $150 \mathrm{~km}$ as neighboring distance.

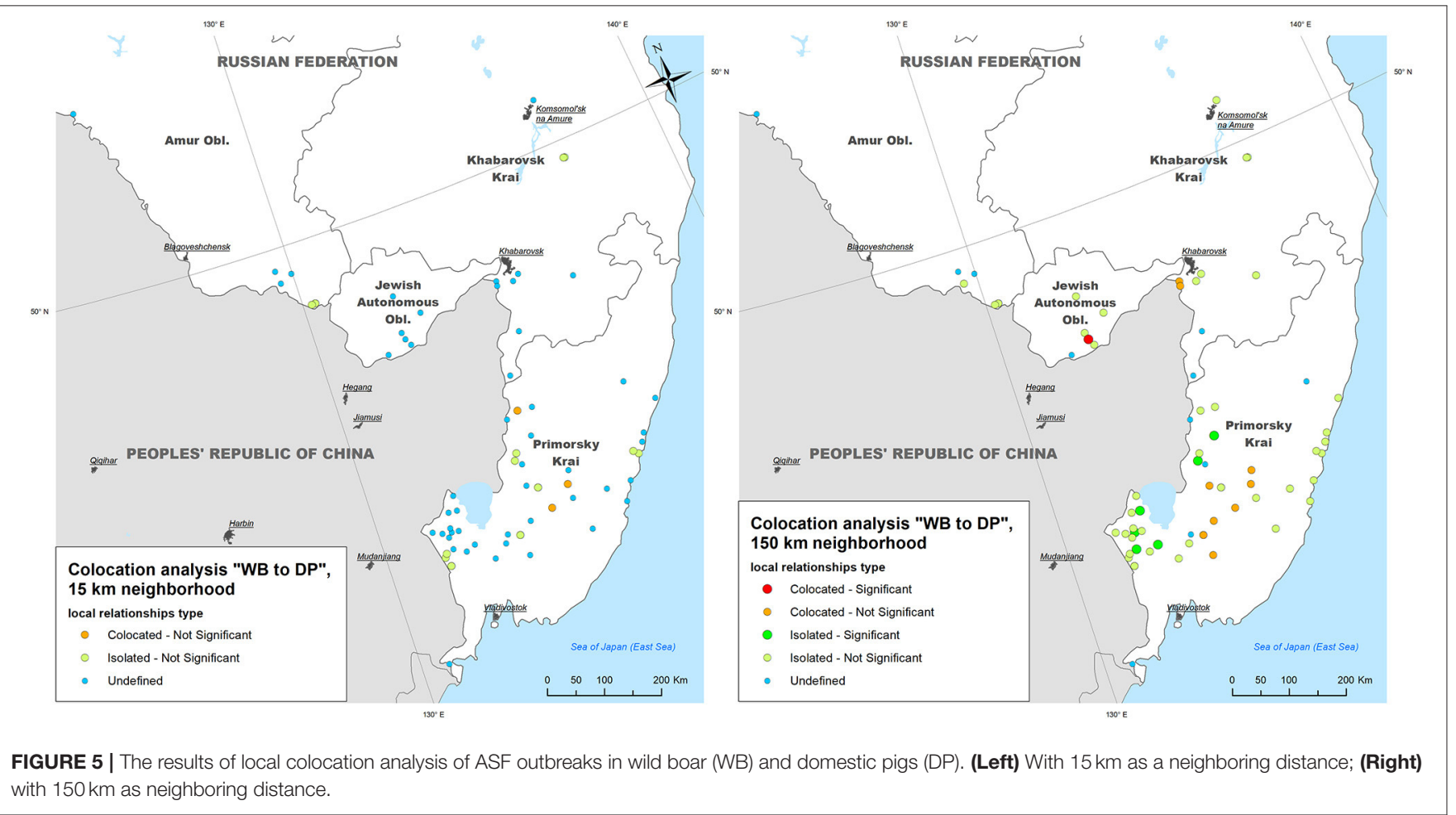

in a large epidemic involving both DP and WB. The current epidemic situation demonstrates a predominance of DP outbreaks in Amur Oblast, Jewish Autonomous Oblast and Khabarovsk Krai. These outbreaks are mainly concentrated along the Russian-Chinese border and main transportation routes with just several cases of ASF in WB that do not influence the outbreak clustering patterns in these three regions. In contrast, Primorsky Krai shows a mixture of ASF 


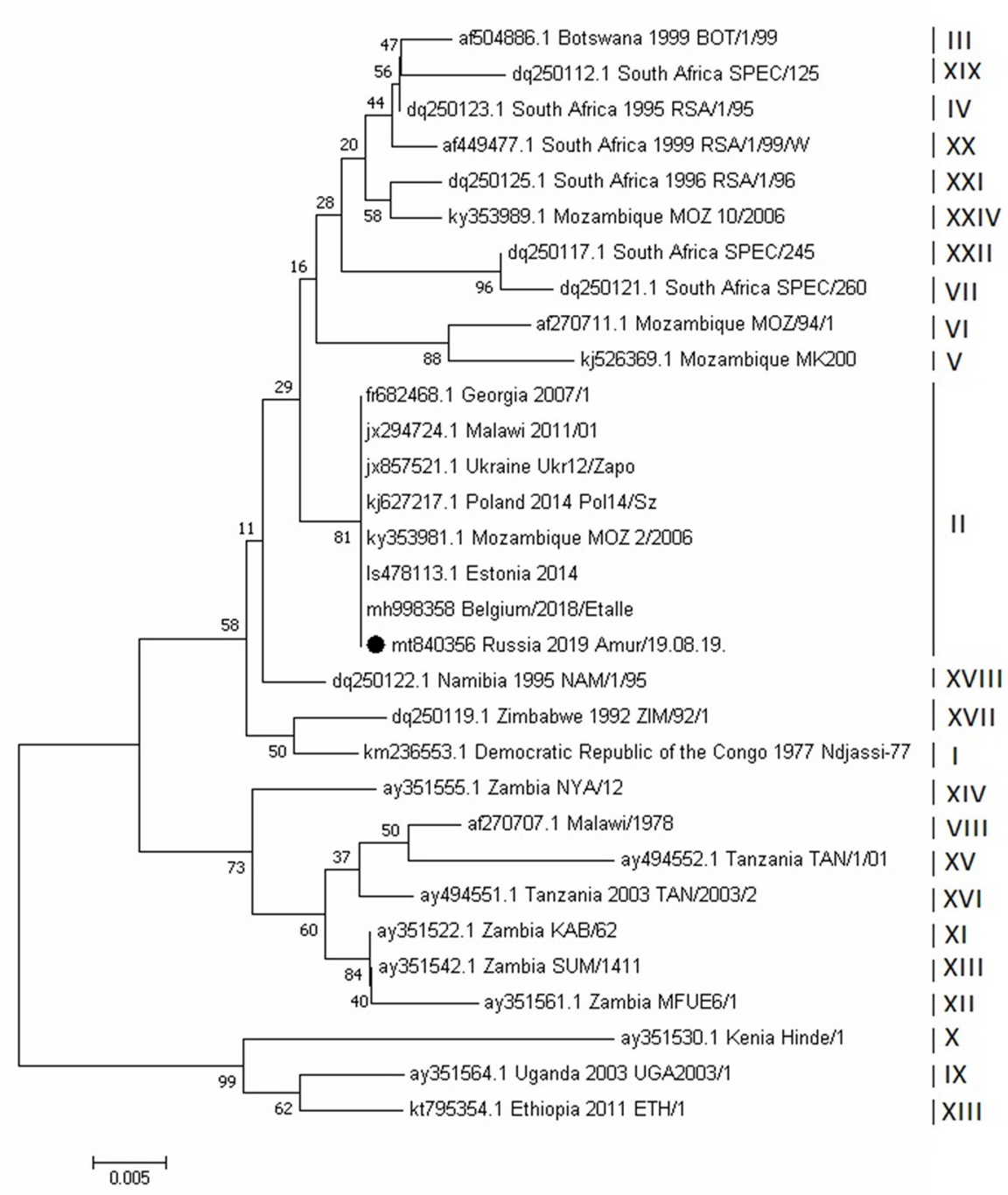

FIGURE 6 | Evolutionary relationships of African swine fever virus strains based on the neighbor-joining phylogeny of the partial p72 gene sequences. The phylogenetic analysis was performed using MEGA7. Bootstrap values (based on 1,000 replicates) for each node are given. GenBank accession numbers, country, and year of collection are indicated for each strain. Corresponding genotypes are labeled I-XXIV. The black circle indicates the African swine fever sequence from Russia, Amur region, 2019. The scale bar indicates nucleotide substitutions per site.

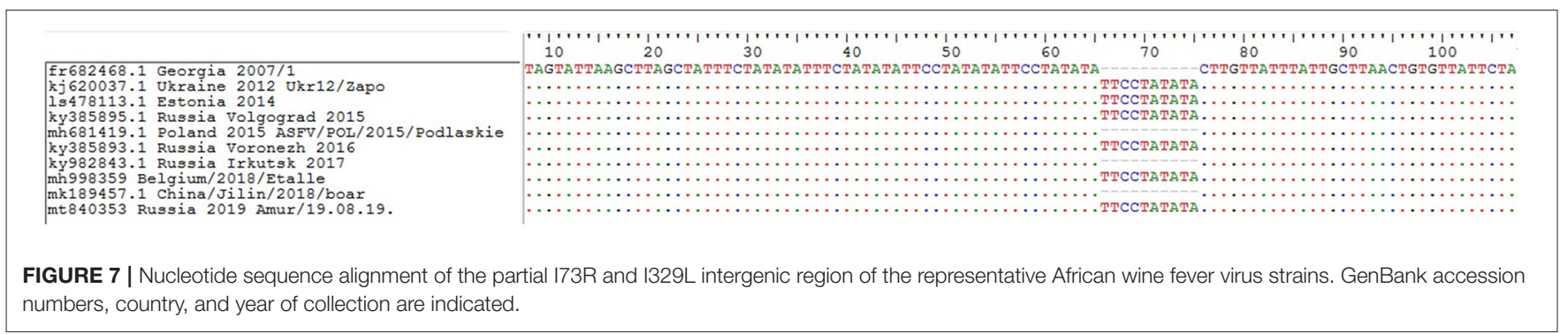

outbreaks both in WB and DP, which are widely spread across its area.

Since the first ASF introduction in the Russian Federation, discussions have been conducted in scientific literature as well as in the media on the leading role of either DP or WB population in the spread of the disease $(3,37,63)$. To shed some light on this question using the example of the new epidemic in Far East of Russia, we explored the space-time relationships between DP 


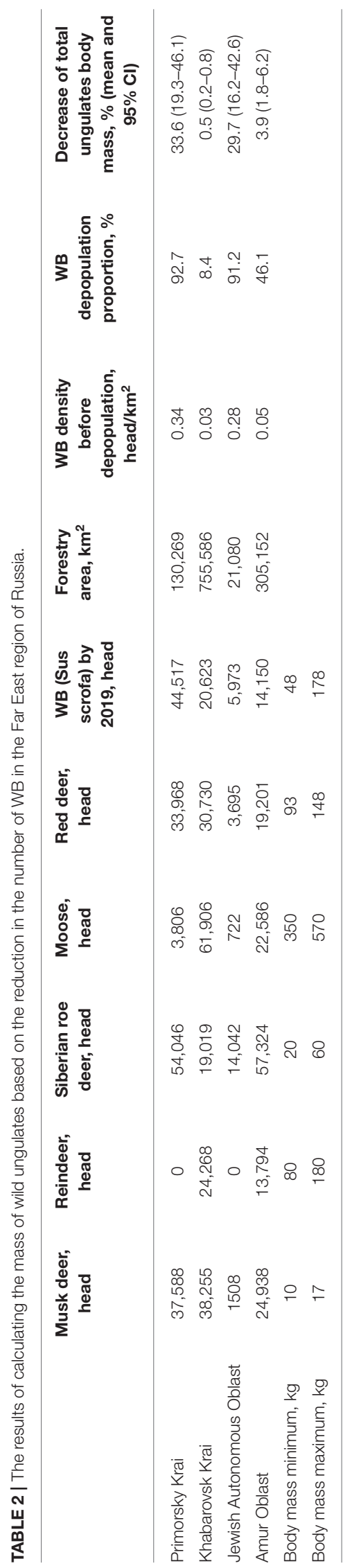

and WB outbreaks by conducting colocation analysis. This type of analysis looks at the elevated concentration of one category of outbreaks within a close proximity to another and may help to reveal a predominant tendency of DP outbreaks emergence after preceding WB cases, or vice versa. However, our results did not indicate any clear pattern of ASF outbreaks' colocation. The most pronounced results are revealed when taking $150 \mathrm{~km}$ as an analysis neighborhood. Most of DP outbreaks, especially in the south-west part of the study area are treated as "isolated" that means an absence or low concentration of WB cases nearby, thus rebutting the hypothesis about the ASF transmission from WB to DP. In Primorsky Krai, the outbreaks' relationships are more heterogeneous, though no obvious pattern is detected as well.

The intensive spread of the ASF virus in the Far Eastern areas of the Russian Federation might have resulted, in part, from insufficient preparedness of the veterinary services and agricultural producers of the region in terms of protection against the virus entry into DP populations. This region has large numbers of poorly protected pig farms, which often practice free range farming techniques, thus with an increased chance for pigs to come into contact with the wild population $(64,65)$. Therefore, according to the "Cerberus" information system at the Federal Service for Veterinary and Phytosanitary Surveillance, 284 out of 289 registered pig-breeding farms in the Primorsky Krai belong to the first or second biosafety level ${ }^{1}$ suggesting low or no biosecurity; in the Khabarovsk Krai, this number is 32 out of 33 farms; in the Jewish Autonomous Oblast, it is 45 out of 45 farms; and in Amur Oblast, it is 2 out of 2 farms. For comparison, in the European part of the Russian Federation, where measures to control the ASF spread have been in place since 2007, the situation is diametrically opposed. In the Belgorod Region (one of the largest agricultural producers in Russia), only 4 out of 371 farms belong to the first or second biosafety level; in the Nizhny Novgorod Region, this number is 22 out of 118 farms; in the Saratov Region, it is 114 out of 183 farms; and in the Volgograd Region, it is 145 out of 235 farms. Although compartmentalization is currently applied to pig producers on a voluntary basis, the above numbers reflect only a part of all pig farms while still being indicative of the ratio between low- and high-biosecurity holdings in the region.

Although some researchers suggest the threshold density of WB that can stop the ASF spread within the population $(4,27$, $66,67)$, other authors advocate that achieving this level does not guarantee the cessation of the epidemic chain $(24,37,68)$. Currently in force national legislation on the ASF prevention and control supposes the WB density reduction in the ASF affected areas till the threshold of 0.025 head $/ \mathrm{km}^{2}$, which may result in an intensive depopulation of WB in the study regions. As a side effect of such a depopulation, a decreased availability of food resources for wild predators of the region can be expected. Particularly, it

\footnotetext{
${ }^{1}$ According to the agricultural producers' biosafety regulations currently in force, all pig-breeding facilities are categorized into four biosafety levels (or compartments). The first and second compartments are considered low or no biosafety holdings, while the third and fourth compartments are large farms with strict biosecurity measures (https://cerberus.vetrf.ru/cerberus/compartment/pub) (Article in Russian).
} 
may affect the population of a protected species, Siberian tigers, for which WB present a significant and easily available food source $(39,40,69,70)$. In our study, we aimed to estimate a possible decrease in the wild ungulates' biomass in a case of the reduction of WB numbers. Such approach is based on several assumptions, which are potential limitations of the study. Other possible limitations include the following:

First, the numbers of all the animals were considered at a regional level, with no differentiation according to the various municipal districts (because of a lack of district-level data).

Second, the average weight of each animal was estimated using a uniform distribution (i.e., all values from minimum to maximum were considered to be equally possible), while the real distributions may be quite different.

Third, not all of an animal's mass is edible meat. In reality, no more than $70 \%$ of its mass can be considered a food resource $(62,69,71)$.

Fourth, we did not account for the age structure of the animal populations, which was partly compensated for by a simulated variation in body mass.

Fifth, according to some studies a prey's population may survive a 1-year withdrawal of $15 \%$ to $25 \%$ of individual animals with no a long-term impact to its numbers (68). This may indicate that a potential impact of depopulation will be most pronounced in the regions with above $25 \%$ estimated depopulation proportion (Table 2).

To carry out a more detailed assessment of the possible impact of a presumable WB depopulation on the equilibrium of the ecosystem, it would be necessary to first have detailed data on the numbers of all animal species at a finer scale (at least the municipal district level), and second, to apply more complex dynamic population models that allow accounting for interactions between the predators and all potential preys.

\section{CONCLUSIONS}

Our results demonstrate the emergence of the ASF virus to the Far Eastern areas of the Russian Federation has led to the rapid spread of the disease over a large territory and support a hypothesis of multiple routes of viral introduction into the region. The ASF virus circulating in the study region demonstrates a close homology with corresponding viruses that have been isolated in Europe, Russia, and China. Due to the

\section{REFERENCES}

1. Penrith ML, Vosloo W. Review of African swine fever: transmission, spread and control. J S Afr Vet Assoc. (2009) 80:58-62. doi: 10.4102/jsava.v80 i2. 172

2. Costard S, Wieland B, De Glanville W, Jori F, Rowlands R, Vosloo W, et al. African swine fever: how can global spread be prevented? Philos Trans R Soc B Biol Sci. (2009) 364:2683-96. doi: 10.1098/rstb.200 9.0098

3. Khomenko S, Beltrán-Alcrudo D, Rozstanlnyy A, Gogin A, Kolbasov D, Pinto J, et al. African Swine Fever in the Russian Federation: Risk Factors for very dense WB population in this region, the ASF virus can be expected to persist in this population, which may entail the artificial regulation of this WB population to prevent the spread of the disease. The possible reduction of the WB population in Primorsky Krai may lead to a $33.6 \%$ (19.3-46.1\%) decrease in the total mass of all ungulates, which may pose a threat to the population of predatory species of the region including the protected population of Siberian tigers.

\section{DATA AVAILABILITY STATEMENT}

The genetic datasets presented in this study can be found in online repositories. The names of the repository/repositories and accession number(s) can be found at: NCBI [accession: MT840352-MT840357]. The data on ASF outbreaks were obtained from open sources, which are indicated in the text.

\section{ETHICS STATEMENT}

The animal study was reviewed and approved by State Veterinary Service of the Russian Federation. Written informed consent was obtained from the owners for the participation of their animals in this study.

\section{AUTHOR CONTRIBUTIONS}

DK: conceptualization and project administration. FK, IT, and AB: methodology. FK and OZ: software and data curation, and visualization. FK, AG, and LA: validation. FK and IT: formal analysis. OZ, AB, and TS: investigation. OZ, LA, and FK: writing-original draft preparation. FK, AG, OZ, and LA: writing-review and editing. AG, LA, and DK: supervision. All authors have read and agree to the published version of the manuscript.

\section{FUNDING}

This work was supported by the Federal Research Center for Virology and Microbiology for government assignment.

\section{ACKNOWLEDGMENTS}

We thank MSc Mackenzie Waltke for proofreading the manuscript.

Europe and Beyond. (2013). Available online at: www.fao.org/ag/empres.html (accessed June 7, 2020).

4. Gervasi V, Marcon A, Bellini S, Guberti V. Evaluation of the efficiency of active and passive surveillance in the detection of African swine fever in wild boar. Vet Sci. (2020) 7:5. doi: 10.3390/vetsci7010005

5. Costard S, Mur L, Lubroth J, Sanchez-Vizcaino JM, Pfeiffer DU. Epidemiology of African swine fever virus. Virus Res. (2013) 173:191-7. doi: 10.1016/j.virusres.2012.10.030

6. Onzere $\mathrm{CK}$, Bastos $\mathrm{AD}$, Okoth EA, Lichoti JK, Bochere EN, Owido MG, et al. Multi-locus sequence typing of African swine fever viruses from endemic regions of Kenya and Eastern Uganda (2011-2013) reveals 
rapid B602L central variable region evolution. Virus Genes. (2018) 54:11123. doi: 10.1007/s11262-017-1521-4

7. Malogolovkin A, Kolbasov D. Genetic and antigenic diversity of African swine fever virus. Virus Res. (2019) 271:197673. doi: 10.1016/j.virusres.2019.197673

8. Malogolovkin A, Burmakina G, Titov I, Sereda A, Gogin A, Baryshnikova E, et al. Comparative analysis of African swine fever virus genotypes and serogroups. Emerg Infect Dis. (2015) 21:312-315. doi: 10.3201/eid2102.140649

9. Wang L, Luo Y, Zhao Y, Gao GF, Bi Y, Qiu HJ. Comparative genomic analysis reveals an 'open' pan-genome of African swine fever virus. Transbound Emerg Dis. (2020) 67:1553-62. doi: 10.1111/tbed.13489

10. Granberg F, Torresi C, Oggiano A, Malmberg M, Iscaro C, De Mia $\mathrm{GM}$, et al. Complete genome sequence of an African swine fever virus isolate from Sardinia, Italy. Genome Announc. (2016) 4:122036. doi: 10.1128 /genomeA.01220-16

11. Gaudreault NN, Madden DW, Wilson WC, Trujillo JD, Richt JA. African swine fever virus: an emerging dna arbovirus. Front Vet Sci. (2020) 7:215. doi: $10.3389 /$ fvets.2020.00215

12. Sánchez-Cordón PJ, Nunez A, Neimanis A, Wikström-Lassa E, Montoya $\mathrm{M}$, Crooke $\mathrm{H}$, et al. African swine fever: disease dynamics in wild boar experimentally infected with ASFV isolates belonging to genotype I and II. Viruses. (2019) 11:852. doi: 10.3390/v11090852

13. Sánchez-Cordón PJ, Montoya M, Reis AL, Dixon LK. African swine fever: a re-emerging viral disease threatening the global pig industry. Vet $J$. (2018) 233:41-8. doi: 10.1016/j.tvjl.2017.12.025

14. Chenais E, Depner K, Guberti V, Dietze K, Viltrop A, Ståhl K. Epidemiological considerations on African swine fever in Europe 2014-2018. Porc Heal Manag. (2019) 5:6. doi: 10.1186/s40813-018-0109-2

15. Galindo I, Alonso C. African swine fever virus: a review. Viruses. (2017) 9:103. doi: 10.3390/v9050103

16. Korennoy FI, Gulenkin VM, Malone JB, Mores CN, Dudnikov SA, Stevenson MA. Spatio-temporal modeling of the African swine fever epidemic in the Russian Federation, 2007-2012. Spat Spatiotemporal Epidemiol. (2014) 11:135-41. doi: 10.1016/j.sste.2014.04.002

17. Bao J, Wang Q, Lin P, Liu C, Li L, Wu X, et al. Genome comparison of African swine fever virus China/2018/AnhuiXCGQ strain and related European p72 Genotype II strains. Transbound Emerg Dis. (2019) 66:116776. doi: 10.1111/tbed.13124

18. Karger A, Pérez-Núñez D, Urquiza J, Hinojar P, Alonso C, Freitas FB, et al. An update on African swine fever virology. Viruses. (2019) 11:864. doi: 10.3390/v11090864

19. Fekede RJ, van Gils H, Huang LY, Wang XL. High probability areas for ASF infection in China along the Russian and Korean borders. Transbound Emerg Dis. (2019) 66:852-64. doi: 10.1111/tbed.13094

20. Liu J, Liu B, Shan B, Wei S, An T, Shen G, et al. Prevalence of African Swine Fever in China, 2018-2019. J Med Virol. (2019) 92:102334. doi: 10.1002/jmv. 25638

21. Vergne T, Korennoy F, Combelles L, Gogin A, Pfeiffer DU. Modelling African swine fever presence and reported abundance in the Russian Federation using national surveillance data from 2007 to 2014. Spat Spatiotemporal Epidemiol. (2016) 19:70-7. doi: 10.1016/j.sste.2016.06.002

22. Pepin KM, Golnar AJ, Abdo Z, Podgórski T. Ecological drivers of African swine fever virus persistence in wild boar populations: insight for control. Ecol Evol. (2020) 10:2846-59. doi: 10.1002/ece3.6100

23. Halasa T, Boklund A, Bøtner A, Mortensen S, Kjær LJ. Simulation of transmission and persistence of African swine fever in wild boar in Denmark. Prev Vet Med. (2019) 167:68-79. doi: 10.1016/j.prevetmed.2019. 03.028

24. Guberti V, Khomenko S, Masiulis M, Kerba S. African Swine Fever in wild Boar Ecology and Biosecurity. FAO Animal Production and Health Manual No. 22. Rome: FAO, OIE and EC (2019).

25. Taylor RA, Condoleo R, Simons RRL, Gale P, Kelly LA, Snary EL. The risk of infection by African swine fever virus in European swine through boar movement and legal trade of pigs and pig meat. Front Vet Sci. (2020) 6:486. doi: 10.3389/fvets.2019.00486

26. Keuling O, Sange M, Acevedo P, Podgorski T, Smith G, Scandura M, et al. Guidance on estimation of wild boar population abundance and density: methods, challenges, possibilities. EFSA Support Publ. (2018) 15:1449E. doi: 10.2903/sp.efsa.2018.EN-1449
27. Podgórski T, Apollonio M, Keuling O. Contact rates in wild boar populations: implications for disease transmission. J Wildl Manage. (2018) 82:12108. doi: $10.1002 /$ jwmg. 21480

28. Jori F, Bastos ADS. Role of wild suids in the epidemiology of African swine fever. Ecohealth. (2009) 6:296-310. doi: 10.1007/s10393-009-0248-7

29. Probst C, Globig A, Knoll B, Conraths FJ, Depner K. Behaviour of free ranging wild boar towards their dead fellows: potential implications for the transmission of African swine fever. $R$ Soc Open Sci. (2017) 4:170054. doi: 10.1098/rsos. 170054

30. Podgórski T, Smietanka K. Do wild boar movements drive the spread of African swine fever? Transbound Emerg Dis. (2018) 65:1588-96. doi: 10.1111/tbed.12910

31. Bieber C, Ruf T. Population dynamics in wild boar Sus scrofa: ecology, elasticity of growth rate and implications for the management of pulsed resource consumers. J Appl Ecol. (2005) 42:1203-13. doi: 10.1111/j.1365-2664.2005.01094.x

32. Zani L, Masiulis M, Bušauskas P, Dietze K, Pridotkas G, Globig A, et al. African swine fever virus survival in buried wild boar carcasses. Transbound Emerg Dis. (2020) 67:2086-92. doi: 10.1111/tbed.13554

33. Morelle K, Jezek M, Licoppe A, Podgorski T. Deathbed choice by ASFinfected wild boar can help find carcasses. Transbound Emerg Dis. (2019) 66:1821-6. doi: 10.1111/tbed.13267

34. Vajas P, Calenge C, Richard E, Fattebert J, Rousset C, Saïd S, et al. Many, large and early: hunting pressure on wild boar relates to simple metrics of hunting effort. Sci Total Environ. (2020) 698:134251. doi: 10.1016/j.scitotenv.2019.134251

35. Urner N, Mõtus K, Nurmoja I, Schulz J, Sauter-Louis C, Staubach C, et al. Hunters' acceptance of measures against African swine fever in wild boar in Estonia. Prev Vet Med. (2020) 182:105121. doi: 10.1016/j.prevetmed.2020.105121

36. Pautienius A, Grigas J, Pileviciene S, Zagrabskaite R, Buitkuviene J, Pridotkas $\mathrm{G}$, et al. Prevalence and spatiotemporal distribution of African swine fever in Lithuania, 2014-2017. Virol J. (2018) 15:177. doi: 10.1186/s12985-018-1090-8

37. More S, Miranda MA, Bicout D, Bøtner A, Butterworth A, Calistri P, et al. African swine fever in wild boar. EFSA J. (2018) 16:e05344. doi: 10.2903/j.efsa.2018.5344

38. Iglesias I, Muñoz MJ, Montes F, Perez A, Gogin A, Kolbasov D, et al. Reproductive ratio for the local spread of African Swine fever in wild boars in the Russian federation. Transbound Emerg Dis. (2016) 63:e23745. doi: 10.1111/tbed.12337

39. Kerley LL, Mukhacheva AS, Matyukhina DS, Salmanova E, Salkina GP, Miquelle DG. A comparison of food habits and prey preference of Amur tiger (Panthera tigris altaica) at three sites in the Russian Far East. Integr Zool. (2015) 10:354-64. doi: 10.1111/1749-4877.12135

40. Dou H, Yang H, Smith JLD, Feng L, Wang T, Ge J, et al. Prey selection of Amur tigers in relation to the spatiotemporal overlap with prey across the Sino-Russian border. Wildlife Biol. (2019) 2019:1-11. doi: 10.2981/wlb.00508

41. Yang H, Dou H, Baniya RK, Han S, Guan Y, Xie B, et al. Seasonal food habits and prey selection of Amur tigers and Amur leopards in Northeast China. Sci Rep. (2018) 8:6930. doi: 10.1038/s41598-018-25275-1

42. Sokolov II. Fauna USSR. Mammals. Ungulate animals. (Detachments Perissodactyla and Artiodactyla). Vol. 1. Academy of Sciences of the USSRin Russian. (1959). p. 642. Available online at: http://biblioclub.ru/index.php? page $=$ book\&id $=114642($ accessed September 23,2020$)$.

43. Danilkin AA. Cervidae (Mammals of Russia and Neighboring Regions). GEOS. (Olenji (Mlekopitayuschie Rossii I sopredelnykh regionov)) - in Russian (1999). p. 552. Available online at: http://geos-books.ru/danilkin-a-a-olenicervidae/ (accessed June 27, 2020).

44. King DP, Reid SM, Hutchings GH, Grierson SS, Wilkinson PJ, Dixon LK, et al. Development of a TaqMan $\AA$ PCR assay with internal amplification control for the detection of African swine fever virus. J Virol Methods. (2003) 107:53-61. doi: 10.1016/S0166-0934(02)00189-1

45. Gallardo C, Fernández-Pinero J, Pelayo V, Gazaev I, Markowska-Daniel I, Pridotkas G, et al. Genetic variation among African swine fever genotype II viruses, Eastern and Central Europe. Emerg Infect Dis. (2014) 20:15447. doi: 10.3201/eid2009.140554

46. Sanna G, Dei Giudici S, Bacciu D, Angioi PP, Giammarioli M, De Mia $\mathrm{GM}$, et al. Improved strategy for molecular characterization of African 
swine fever viruses from Sardinia, based on analysis of p30, CD2V and I73R/I329L variable regions. Transbound Emerg Dis. (2017) 64:12806. doi: $10.1111 /$ tbed. 12504

47. Nix RJ, Gallardo C, Hutchings G, Blanco E, Dixon LK. Molecular epidemiology of African swine fever virus studied by analysis of four variable genome regions. Arch Virol. (2006) 151:247594. doi: 10.1007/s00705-006-0794-z

48. Bastos ADS, Penrith ML, Crucière C, Edrich JL, Hutchings G, Roger F, et al. Genotyping field strains of African swine fever virus by partial p72 gene characterization. Arch Virol. (2003) 148:693-706. doi: 10.1007/s00705-002-0946-8

49. Lubisi BA, Bastos ADS, Dwarka RM, Vosloo W. Intra-genotypic resolution of African swine fever viruses from an East African domestic pig cycle: a combined p72-CVR approach. Virus Genes. (2007) 35:72935. doi: 10.1007/s11262-007-0148-2

50. BioEdit: A User-Friendly Biological Sequence Alignment Editor and Analysis Program for Windows 95/98/NT - ScienceOpen. Available online at: https://www.scienceopen.com/document?vid=8b59b929-3c37-49f6-936bf8bf6dd92ace (accessed September 20, 2020).

51. Thompson JD, Gibson TJ, Plewniak F, Jeanmougin F, Higgins DG. The CLUSTAL X windows interface: flexible strategies for multiple sequence alignment aided by quality analysis tools. Nucleic Acids Res. (1997) 25:487682. doi: $10.1093 /$ nar/25.24.4876

52. Kimura M. A simple method for estimating evolutionary rates of base substitutions through comparative studies of nucleotide sequences. J Mol Evol. (1980) 16:111-20. doi: 10.1007/BF01731581

53. Kumar S, Stecher G, Tamura K. MEGA7: molecular evolutionary genetics analysis version 7.0 for bigger datasets. Mol Biol Evol. (2016) 33:18704. doi: $10.1093 / \mathrm{molbev} / \mathrm{msw} 054$

54. Space-Time Permutation Model, Kulldorff M, Heffernan R, Hartman J, Assunção RM, Mostashari F. A space-time permutation scan statistic for disease outbreak detection. PLoS Med. (2005) 2:216-24. doi: 10.1371/journal.pmed.0020059

55. Burt, JE, Barber GM. Elementary Statistics for Geographers. 2nd ed. New York, NY: Guilford Press (1996).

56. How Colocation analysis works. ArcGIS Pro Online Help. Esri (2021). Available online at: https://pro.arcgis.com/en/pro-app/latest/tool-reference/ spatial-statistics/learnmorecolocationanalysis.htm (accessed January 31, 2021).

57. Leslie TF, Kronenfeld BJ. The colocation quotient: a new measure of spatial association between categorical subsets of points. Geograph Analy. (2011) 43:306-26. doi: 10.1111/j.1538-4632.2011.00821.x

58. Wang $\mathrm{F}, \mathrm{Hu}$ Y, Wang S, Li X. Local indicator of colocation quotient with a statistical significance test: examining spatial association of crime and facilities. Profess Geograph. (2017) 69:22-31. doi: 10.1080/00330124.2016.1157498

59. Kulldorff M. Software for the Spatial and Space-Time Scan Statistics. Information Management Services, Inc. SaTScan ${ }^{\mathrm{TM}}$ v9.6. (2018). Available online at: www.satscan.org (accessed May 9, 2021).

60. Malkhazova S, Korennoy F, Petrova O, Gulenkin V, Karaulov A. Spatio-temporal analysis of the local African swine fever epidemics in the Russian Federation, 2007-2015. Front Vet Sci. (2019). doi: 10.3389/conf.fvets.2019.05.00018

61. On the Acceptance of the Veterinary Rules of Conducting Prophylactic, Diagnostic, Restriction and Other Measures, Quarantine Establishing and Dropping, and Other Restrictions Aimed at the Prevention of the African Swine Fever Spread and Eradication of Its Foci. The decree of the Ministry of Agriculture of the Russian Federation from 28 January 2021 \#37 (in Russian) (2021). Available online at: https://docs.cntd.ru/document/ 573473462? marker=6500IL\#/reg (accessed May 5, 2021).

62. Maksimova DA, Seryodkin I V., Zaitsev VA, Miquelle DG. Research program of musk deer ecology in the sikhote-alin region. Achiev Life Sci. (2014) 8:65-71. doi: 10.1016/j.als.2014.11.005

63. Bellini S, Rutili D, Guberti V. Preventive measures aimed at minimizing the risk of African swine fever virus spread in pig farming systems. Acta Vet Scand. (2016) 58:82. doi: 10.1186/s13028-016-0264-x

64. Cappai S, Rolesu S, Coccollone A, Laddomada A, Loi F. Evaluation of biological and socio-economic factors related to persistence of African swine fever in Sardinia. Prev Vet Med. (2018) 152:1-11. doi: 10.1016/j.prevetmed.2018.01.004

65. Mur L, Sánchez-Vizcaíno JM, Fernández-Carrión E, Jurado C, Rolesu S, Feliziani F, et al. Understanding African Swine Fever infection dynamics in Sardinia using a spatially explicit transmission model in domestic pig farms. Transbound Emerg Dis. (2018) 65:123-34. doi: 10.1111/tbed. 12636

66. Olševskis E, Schulz K, Staubach C, SerŽants M, Lamberga K, Pule D, et al. African swine fever in Latvian wild boar-a step closer to elimination. Transbound Emerg Dis. (2020) 67:2615-29. doi: 10.1111/tbed.13611

67. Pejsak Z, Truszczyński M, Niemczuk K, Kozak E, Markowska-Daniel I. Epidemiology of African Swine Fever in Poland since the detection of the first case. Pol J Vet Sci. (2014) 17:665-72. doi: 10.2478/pjvs-2014-0097

68. Danilkin AA. Management of Wild Boar and Other Animal Resources in African Swine Fever. (2020). Available online at: https://www.litres.ru/a-adanilkin/upravlenie-resursami-kabana-i-drugih-zhivotnyh-pri-a-51267507/

69. Biswas S, Sankar K. Prey abundance and food habit of tigers (Panthera tigris tigris) in Pench National Park, Madhya Pradesh, India. J Zool. (2006) 256:411-20. doi: 10.1017/S0952836902000456

70. Rozhnov VV, Aramileva TS, Gaponov VV, Darman YA, Zhuravlev YN, Kostyrya AV, et al. A Strategy of the Siberian Tiger Preservation in the Russian Federation. Moscow: Ministry of natural resources and ecology of the Russian Federation (in Russian). (2010). p. 49. Available online at: http://amur-tiger. ru/assets/docs/strategita-tigr-russ.pdf (last accessed May 9, 2021).

71. Ramesh T, Snehalatha V, Sankar K, Qureshi Q. Food habits and prey selection of tiger and leopard in Mudumalai Tiger Reserve, Tamil Nadu, India. Sci Trans Enviorn Technov. (2009) 2:170-81. doi: 10.20894/stet.116.002.003.010

Conflict of Interest: The authors declare that the research was conducted in the absence of any commercial or financial relationships that could be construed as a potential conflict of interest.

Publisher's Note: All claims expressed in this article are solely those of the authors and do not necessarily represent those of their affiliated organizations, or those of the publisher, the editors and the reviewers. Any product that may be evaluated in this article, or claim that may be made by its manufacturer, is not guaranteed or endorsed by the publisher.

Copyright (C) 2021 Zakharova, Titov, Gogin, Sevskikh, Korennoy, Kolbasov, Abrahamyan and Blokhin. This is an open-access article distributed under the terms of the Creative Commons Attribution License (CC BY). The use, distribution or reproduction in other forums is permitted, provided the original author(s) and the copyright owner(s) are credited and that the original publication in this journal is cited, in accordance with accepted academic practice. No use, distribution or reproduction is permitted which does not comply with these terms. 